\title{
Seasonal trends in the prevalence of hypospadias: Aetiological implications
}

\author{
C. MAMOULAKIS ${ }^{1}$, G. AVGENAKIS ${ }^{1}$, C. GKATZOUDI ${ }^{2}$, G. DUIJKER ${ }^{2}$, I.E. ZISIS ${ }^{1}$, I. HERETIS ${ }^{1}$,

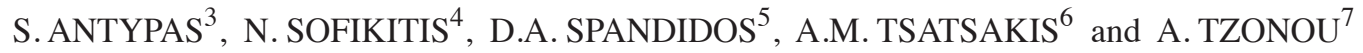 \\ ${ }^{1}$ Department of Urology, University General Hospital of Heraklion, University of Crete Medical School; \\ ${ }^{2}$ Clinic of Social and Family Medicine, Faculty of Medicine, University of Crete, Heraklion 71003; \\ ${ }^{3}$ First Pediatric Surgery Clinic, Aghia Sophia Children's Hospital, Athens 11527; ${ }^{4}$ Department of Urology, \\ University of Ioannina, Medical School, Ioannina 45110; ${ }^{5}$ Laboratory of Clinical Virology, Medical School, \\ and ${ }^{6}$ Department of Forensic Sciences and Toxicology, Faculty of Medicine, University of Crete, Heraklion 71003; \\ ${ }^{7}$ Department of Hygiene, Epidemiology and Medical Statistics, University of Athens, Medical School, Athens 11527, Greece
}

Received January 24, 2017; Accepted March 28, 2017

DOI: $10.3892 / \mathrm{etm} .2017 .4323$

\begin{abstract}
The aim of the present study was to examine the seasonality of hypospadias in Greece in an attempt to elucidate the aetiology. All boys born between 1991-1998, who underwent hypospadias repair at 'Aghia Sophia' Children's Hospital, Athens $(n=542)$ were analysed. All Greek live-born males during the same period (population at risk; $m=421,175$ ) served as the controls. Seasonality by month of birth was evaluated with specific statistical tools. Meteorological parameters were also analysed. All tests yielded significant results, suggesting a simple harmonic prevalence pattern (highest/lowest: autumn, peak in October/spring, trough in April). Therefore, the first trimester of hypospadiac gestations coincides more frequently with winter. Meteorological parameters varied seasonally (maximal sunlight; air temperature in summer/minimal in winter, maximal rainfall in winter/minimal in summer) and were strongly associated pairwise. Hypospadiac birth prevalence follows a simple harmonic seasonal pattern and is associated with that of cryptorchidism in Greece. The coincidence of the first or third trimester of a potentially genetically influenced gestation with winter could lead to the phenotypic expression of hypospadias or cryptorchidism, respectively. The potential role of a cyclic-varied androgen-production stimulator, such as human chorionic gonadotrophin may be speculated. The seasonality of a common environmental factor acting directly/indirectly may contribute to these patterns, and possibly to the common pathogenesis of these congenital malformations.
\end{abstract}

Correspondence to: Professor C. Mamoulakis, Department of Urology, University General Hospital of Heraklion, Voutes, University of Crete Medical School, Heraklion 71003, Crete, Greece

E-mail:mamoulak@uoc.gr

Key words: congenital anomaly, epidemiology, hypospadias, prevalence, seasonal variation

\section{Introduction}

Hypospadias is a relatively common congenital malformation with a total prevalence of 18.61 per 10,000 male live births reported in Europe, remaining stable during the previous decade (1). The aetiology of this condition is obscure, with a general agreement on its multifactorial nature assuming the cooperation of genetic factors with exogenous factors, disrupting the male sex hormone axis (2-6). It is associated with other defects, particularly with cryptorchidism $(7,8)$. Several risk factors have been reported; however, not all of them are uniformly accepted. Seasonality stands as a common component of the basic aetiological description for congenital abnormalities. Infections early in pregnancy for example, represent a theoretical risk for any birth defect. If infectious agents potentially linked to hypospadias include some that are common at particular times of the year, their seasonal variation may be reflected in the pattern of month of birth (MB) of affected males (9). Thus, seasonal variations (SV) of hypospadiac prevalence have been widely investigated worldwide, particularly in the past, with conflicting results; some authors have reported significant variations, while others have not (please see below).

In the present study, in an attempt to elucidate the aetiology, a retrospective analysis was performed on hypospadiac births (HB) in Greece, based on the strict use of statistical tools specifically designed for investigating SV of congenital malformations.

\section{Materials and methods}

All Greek boys born within the period 1991-1998 who underwent hypospadias repair at a major pediatric center in Athens (Aghia Sophia Children's Hospital) comprised the study population $(\mathrm{n}=542)$. All live-born boys within the same period comprised the population at risk $(m=421,175)$ and served as the controls. Data on the study population were accrued through the center's Statistical Department. Data on the population at risk were collected from the Hellenic Statistical 
Authority. Three meteorological parameters were analysed per month for the period 1990-1998 to include the intrauterine life of all study population subjects: i) air temperature; ii) rainfall amount; and iii) sunshine duration. Data were provided from the Institute of Environmental Research and Sustainable Development (IERSD). The decision to consider these parameters was based on the ability to be measured accurately/independently from potential confounders.

Temporal analysis was based on dates of birth using three popular 'specific' tests as follows: Edwards' test (10), Hewitt's test [rank-sum (RS) method] (11) corrected by Rockenbauer (12) and Walter-Elwood's test (13). Data were analysed per month making adjustments to achieve exact month lengths in degrees. The February length was considered $28+2 / 8$ days with adjustment for the total year to include $365+2 / 8$ days (two leap years; 1992 and 1996). Considering this period as a circular unit, the accurate mean January duration is $31 \times 360 / 365.25=30.55^{\circ}\left(0-30.55^{\circ}\right)$ and that for February is $28.25 \times 360 / 365.25=27.84^{\circ}\left(30.55-58.40^{\circ}\right)$. Correction factors were used for Edwards' test to compute adjusted monthly frequencies $\left(n_{i}^{\prime}\right)$ for the variable population at risk. Based on $\mathrm{n}_{\mathrm{i}}{ }^{\prime}$, months were ranked from 12 (highest prevalence) down to 1 (lowest prevalence), to locate the six-month period of maximum prevalence by calculating maximum RS (11). RS $\geq 55$ [or $\leq 23$ (12)] was considered significant at the 5\% level; Hewitt's test results were evaluated under the assumption that no prior hypothesis exists specifying the six-month period of higher expected prevalence (11). Considering data following a cyclic pattern described by a simple harmonic curve, assuming one peak/one trough of an annual cycle separated by a six-month interval, the SV magnitude was calculated using the amplitude $(\alpha)$ of the sinusoidal oscillation and the angle (time) of maximum/minimum prevalence $\left(\theta_{\max } / \theta_{\min }\right)$. To examine data description adequacy by such a curve, expected monthly frequencies for Edwards' $\left(\mathrm{E}_{\mathrm{Ei}}\right)$ and Walter-Elwood's test $\left(\mathrm{E}_{\mathrm{Wi}}\right)$ were computed; $E_{E i}$ vs. $n_{i}^{\prime}$ and $E_{W i}$ vs. $n_{i}^{\prime}$ were compared using the $\chi^{2}$ goodness-of-fit test. Hewitt's test was applied independently to check Edwards' test application appropriateness. Walter-Elwood's test was used to unmask additional co-existing peaks. In addition, we also applied periodic regression, in which the underlying equation has a sinusoidal form. We fitted a sine curve to the $\mathrm{n}_{\mathrm{i}}{ }^{\prime}$ and we estimated $95 \%$ confidence interval (CI) for the peak to low ratios $(9,14,15)$.

Data were analysed using a Microsoft Excel application (Four Seasons Plus.xls) created and validated for the present study, IBM SPSS Statistics for Windows, version 23.0 (IBM Corp.; Armonk, NY, USA) and R statistical package [R Core Team (2017). R: A language and environment for statistical computing. R Foundation for Statistical Computing, Vienna, Austria. URL http://www.R-project.org/.]. A two-tailed value of $\mathrm{P} \leq 0.050$ was considered to indicate a statistically significant difference.

\section{Results}

The mean, minimum and maximum values of air temperature were $17.8^{\circ} \mathrm{C}, 6.7^{\circ} \mathrm{C}$ (December 1991) and $29.8^{\circ} \mathrm{C}$ (July and August 1998). The respective values of rainfall amounts were: 30.2 mm, 0 mm (1990: June, July; 1991: June, September; 1992: August, September; 1993: June, July, September, October; 1994:

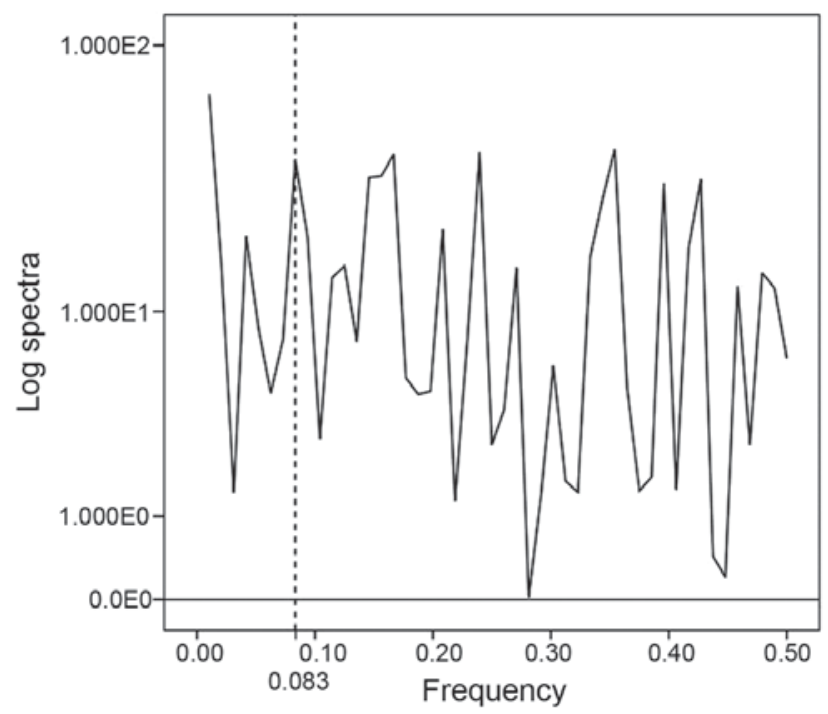

Figure 1. Periodogram of the adjusted monthly frequencies of hypospadiac births $\left(\mathrm{n}_{\mathrm{i}}^{\prime}\right)$ revealing a trend towards a sinusoidal annual periodicity. Sinusoidal periodic components are shown as single peaks. An annual component implies a peak at a frequency of 0.083 (each of the data points in the time series represents a month; an annual periodicity corresponds to a period of 12 in the current data set i.e., a frequency of $1 / 12=0.083$ ).

August, September; 1996: June, July; 1997: July; 1998: July, August) and $184.7 \mathrm{~mm}$ (November 1998). The respective values of sunshine duration were $237.0 \mathrm{~h}, 62.9 \mathrm{~h}$ (January 1996) and $406.2 \mathrm{~h}$ (July 1998). The meteorological parameters presented SV annually and collectively through the study period with strong pairwise association (air temperature-sunshine duration, air temperature-rainfall amount, sunshine duration-rainfall amount: Pearson's $\mathrm{r}=0.95,-0.88$ and -0.93 , respectively; $\mathrm{P}<0.001)$.

Spectral analysis performed on HB to detect potential periodic patterns revealed a trend towards a sinusoidal annual periodicity (Fig. 1). The monthly HB frequency distribution is shown in Table I. Edwards' test yielded maximum prevalence in late October $\left(\theta_{\max }=294.60^{\circ}\right) /$ minimum in late April $\left(\theta_{\min }=114.60^{\circ}\right)\left(\mathrm{X}_{2}^{2}=7.92 ; \mathrm{P}<0.020\right)$. The hypothesised simple harmonic curve that observed frequencies were fitted on had an amplitude of $\alpha=0.171$. There was insignificant departure of adjusted frequencies from the curve $\left(\mathrm{X}_{11}^{2}=13.24\right.$; P>0.200). Rockenbauer-corrected Hewitt's test (12) indicated significantly more HB from August to January (Table I; maximum $\mathrm{RS}=55 ; \mathrm{P}=0.004)$. Walter-Elwood's test yielded similar results: sole peak in mid-October $\left(\theta_{\max }=288.40^{\circ}\right) /$ sole trough in mid-April $\left(\theta_{\min }=108.40^{\circ}\right)\left(\mathrm{X}_{2}^{2}=8.85 ; \mathrm{P}<0.020\right)$ (Fig. 2). The amplitude of the expected frequency curve was 0.168 . The expected frequency curve revealed significantly greater rates in autumn. No significant departure of observed frequencies from the fitted simple harmonic curve were detected (13.64, $\mathrm{P}>0.200$ ) (Fig. 3).

Periodic regression confirmed the results yielded by Edwards' and Walter-Elwood's tests. The estimate for the relative risk (RR; maximum over minimum probability of having the event across seasons) was 1.40 (95\% CI, 1.10-1.78; $\mathrm{P}=0.022)$ with a peak at $288^{\circ}(95 \%$ CI using the normal approximation, $\left.248-328^{\circ}\right)$, namely at mid-October (95\% CI, early-September-late November). 
Table I. Hypospadias: Data from the Greek population (1991-1998).

\begin{tabular}{|c|c|c|c|c|c|c|}
\hline \multirow{2}{*}{$\begin{array}{l}\text { Month } \\
\text { of birth }\end{array}$} & \multirow{2}{*}{$\begin{array}{l}\text { Total male } \\
\text { live births } \\
\qquad\left(\mathrm{m}_{\mathrm{i}}\right)\end{array}$} & \multirow{2}{*}{$\begin{array}{l}\text { Observed frequencies } \\
\text { of hypospadiac births } \\
\qquad\left(\mathrm{n}_{\mathrm{i}}\right)\end{array}$} & \multirow{2}{*}{$\begin{array}{l}\text { Adjusted frequencies } \\
\text { of hypospadiac births }{ }^{\text {a }} \\
\qquad\left(\mathrm{n}_{\mathrm{i}}^{\prime}\right)\end{array}$} & \multirow{2}{*}{$\begin{array}{c}\text { Rank order of } \\
\text { months (based on } \\
\text { adjusted frequencies) }\end{array}$} & \multicolumn{2}{|c|}{$\begin{array}{l}\text { Expected frequencies } \\
\text { of hypospadiac births }\end{array}$} \\
\hline & & & & & $\left(\mathrm{E}_{\mathrm{Ei}}\right)$ & $\left(\mathrm{E}_{\mathrm{Wi}}\right)$ \\
\hline January & 33,346 & 46 & 48.5 & 10 & 46.4 & 43.2 \\
\hline February & 31,423 & 43 & 48.1 & 8 & 42.6 & 37.4 \\
\hline March & 33,851 & 44 & 45.7 & 4 & 39.4 & 37.5 \\
\hline April & 33,338 & 24 & 25.3 & 1 & 37.6 & 35.7 \\
\hline May & 36,261 & 33 & 32.0 & 2 & 37.9 & 39.5 \\
\hline June & 35,167 & 47 & 47.0 & 5 & 40.1 & 40.9 \\
\hline July & 39,001 & 46 & 41.5 & 3 & 43.7 & 49.5 \\
\hline August & 37,144 & 66 & 62.5 & 12 & 47.8 & 51.2 \\
\hline September & 36,346 & 50 & 48.4 & 9 & 51.1 & 53.2 \\
\hline October & 36,526 & 49 & 47.1 & 6 & 52.8 & 54.8 \\
\hline November & 34,060 & 46 & 47.5 & 7 & 52.4 & 50.3 \\
\hline December & 34,712 & 48 & 48.6 & 11 & 50.1 & 48.7 \\
\hline Total & 421,175 & 542 & 542 & 78 & 542 & 542 \\
\hline
\end{tabular}

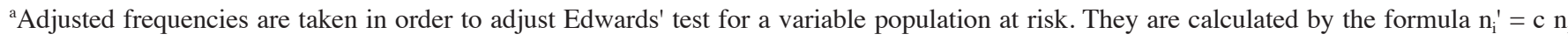
$\Sigma \mathrm{mi} / \mathrm{k}$ mi, where c is a scale factor such that $\Sigma \mathrm{n}_{\mathrm{i}}^{\prime}=\Sigma \mathrm{n}_{\mathrm{i}}$ and $\mathrm{k}$ is the number of the sectors in which the given time span (one year) is divided (i.e., $\mathrm{k}=12$ here) $\mathrm{E}_{\mathrm{Ei}}$ are proportional to $\left[1+\alpha \operatorname{Cos}\left(\theta_{\mathrm{i}}-\theta_{\max }\right)\right]$, and $\mathrm{E}_{\mathrm{wi}}$ are proportional to $\left\{\mathrm{m}_{\mathrm{i}}\left[1+\alpha \operatorname{Cos}\left(\theta_{\mathrm{i}}-\theta_{\max }\right)\right]\right\}$. $\mathrm{E}_{\mathrm{Ei}}$, expected frequencies for Edwards' test; $\mathrm{E}_{\mathrm{wi}}$, expected frequencies for Walter-Elwood's test. ${ }^{b}$ Months are ranked from 12 (highest prevalence) to 1 (lowest prevalence) for the calculation of the maximum rank sum (RS) that locates the period of 6 consecutive months showing the maximum prevalence (here: $\mathrm{RS}=55$ for August-January).

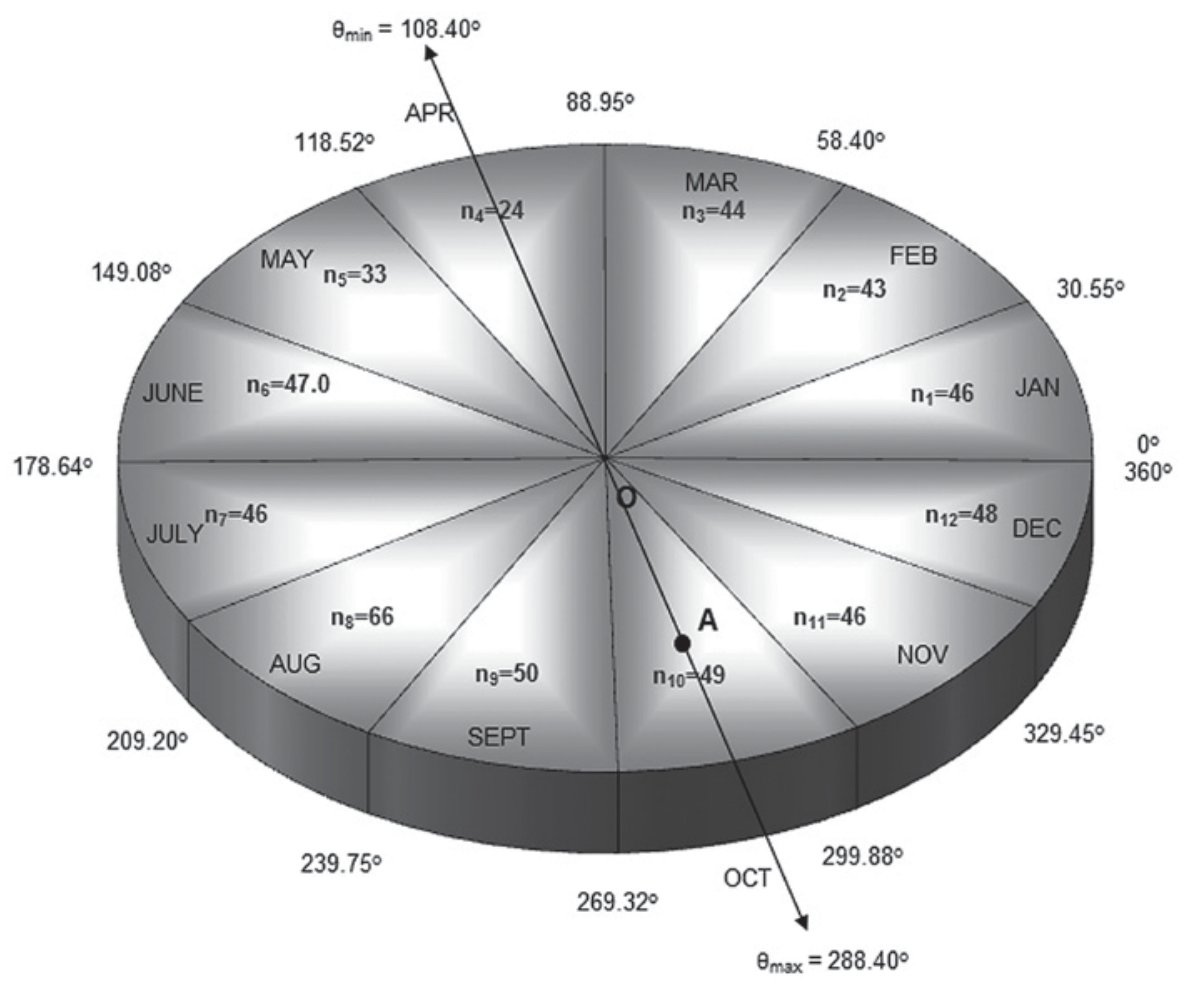

Figure 2. Walter-Elwood's model in hypospadias: data from the Greek population (1991-1998).

\section{Discussion}

The investigation of seasonality is used for the basic aetiological description of congenital malformations. If there are
SV in the prevalence of a malformation, then these should be shown by adequate analysis; these should occur mostly in non-tropical areas where seasons are well defined (16). Specific statistical tools have been developed in the past for 


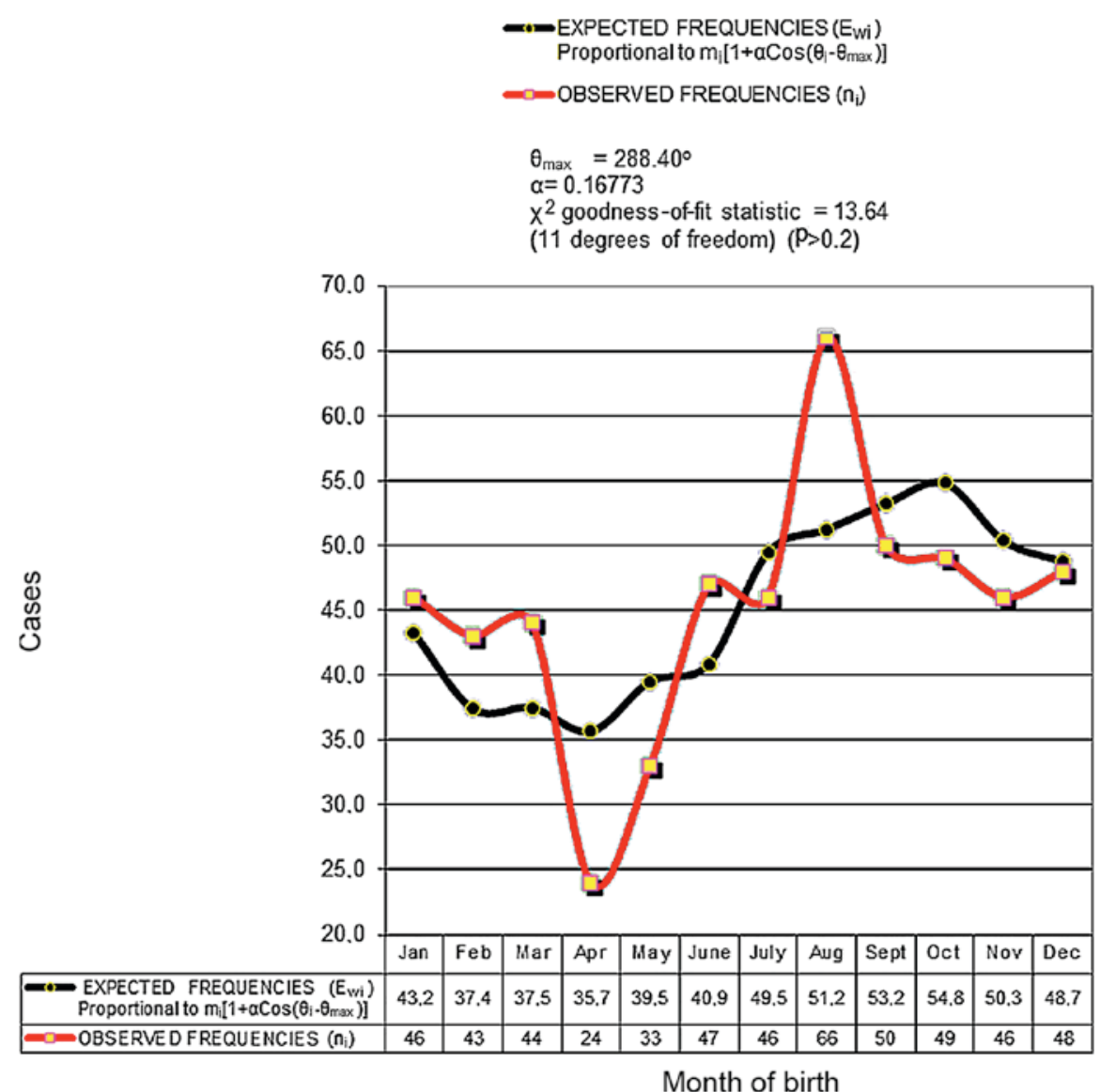

Figure 3. Observed frequencies fitted into the simple harmonic curve given by Walter Elwood's test. Evaluation of the adequacy of data description with $\chi^{2}$ goodness-of-fit test.

the investigation of seasonality in congenital malformations. Modern methods for the analysis of this type of data have also been recently developed, such as regression analysis supplemented by sine and cosine functions (17) and periodic regression $(9,14,15)$. We opted to use these 'old tests', in order for our study to be potentially comparable in terms of methodology with the vast majority of studies in the field, which were published many years ago. Nevertheless, we also applied 'modern techniques' (periodic regression) to ensure the validity of our results $(9,14,15)$.

Among the 'old tests', Edwards' test occupies a central place in such analyses. It neglects variations in population at risk, possibly responsible for the apparent seasonality in the prevalence (e.g., due to variability in total births among months), assuming equal time intervals. Walter and Elwood's generalization (13) overcomes these limitations, considering variation in the population at risk. Edwards' method has been criticised to be sensitive to cyclic variations not of simple harmonic form (18). Hewitt's test (11), later corrected by Rockenbauer (12), detects simple harmonic patterns being more critical to meandering and distinguishes harmonic from non-harmonic variations, but lacks the power of parametric methods for moderate sample sizes and does not estimate curve parameters (13).

The most effective means to study seasonality is to perform Edwards' and Hewitt's tests independently $(11,19)$. The results of Hewitt's test should be evaluated under the assumption that no prior hypothesis exists specifying the six-month period of higher expected prevalence. The result is significant if $\mathrm{RS} \geq 55$ (or $\leq 23$; Rockenbauer's correction). Only defects yielding significant results by independently applying both tests are regarded of definite harmonic behavior. Discordance between the Edwards' test/RS method makes findings difficult to interpret (20). Apart from the 'specific' tools for detecting seasonality, the use of $\chi^{2}$ of heterogeneity across $\mathrm{k}$ time periods [e.g., 12 months of the year $(\mathrm{k}=12)$ in our study] could be considered. However, the power of Edwards' test is higher (19). This tool was used in the past, but has been abandoned nowadays and, if ever used, it is obligatorily supplemented by a 'specific' statistical tool, since the results produced cannot be unequivocally accepted; significant results do not necessarily imply a seasonal pattern, insignificant results cannot rule out a seasonal pattern.

We conducted a systematic literature search up to November 16, 2016, using Medline, in an attempt to detect all relevant reports published to date, and we tried to compare their results with ours. No temporal, regional, publication status or language restrictions were set. The search included the following keywords: hypospadias, epidemiology, prevalence, season, month, birth, variation and time-series, in all relevant combinations, as well as a complete separate literature search strategy (LSS) as follows: [hypospadias AND (epidemiology OR prevalence OR season OR month OR birth OR variation OR time-series); filter: human]. The reference lists of selected reports were further reviewed for relevance. Methodologically non-focused reports on the seasonality of hypospadias 


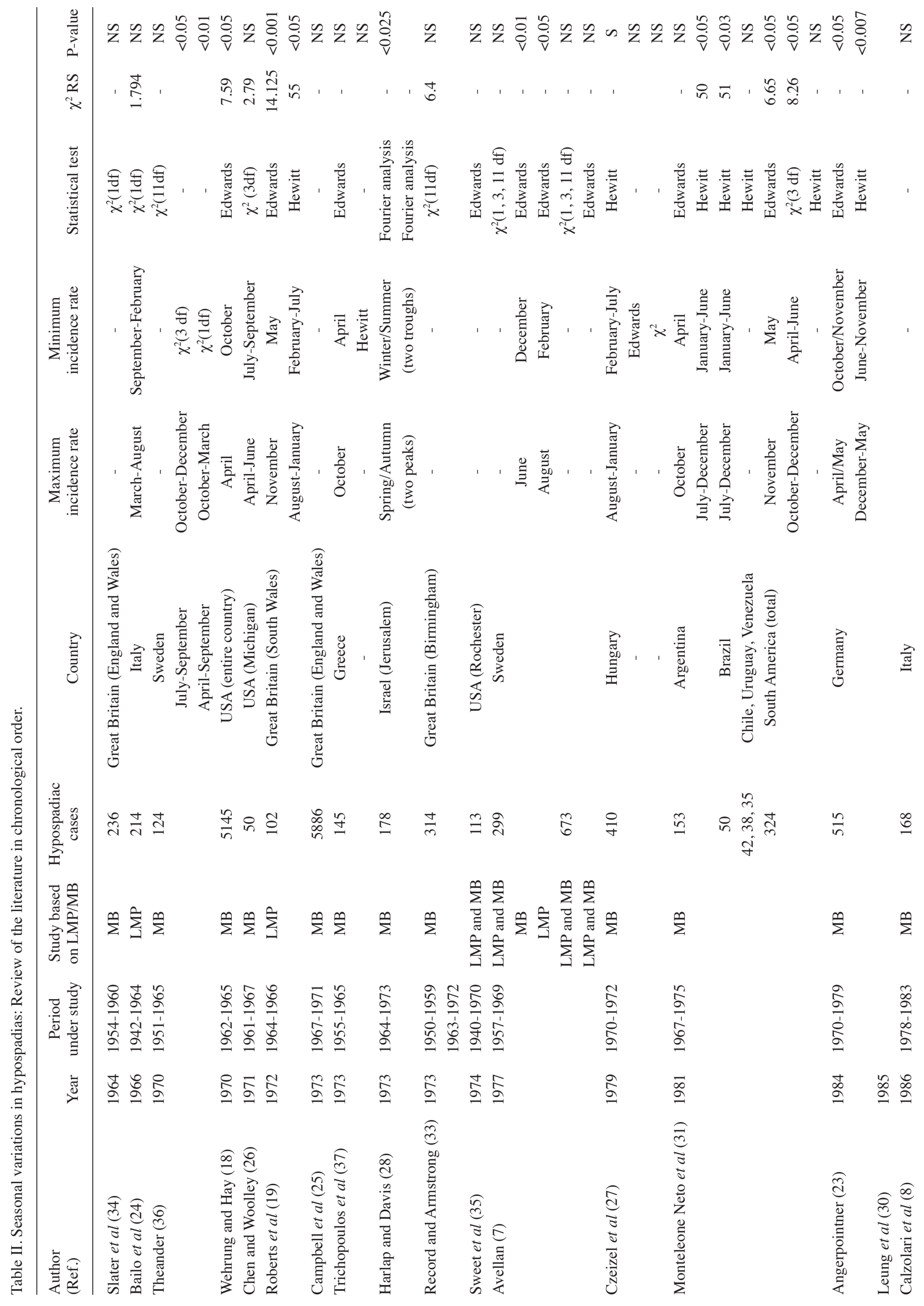




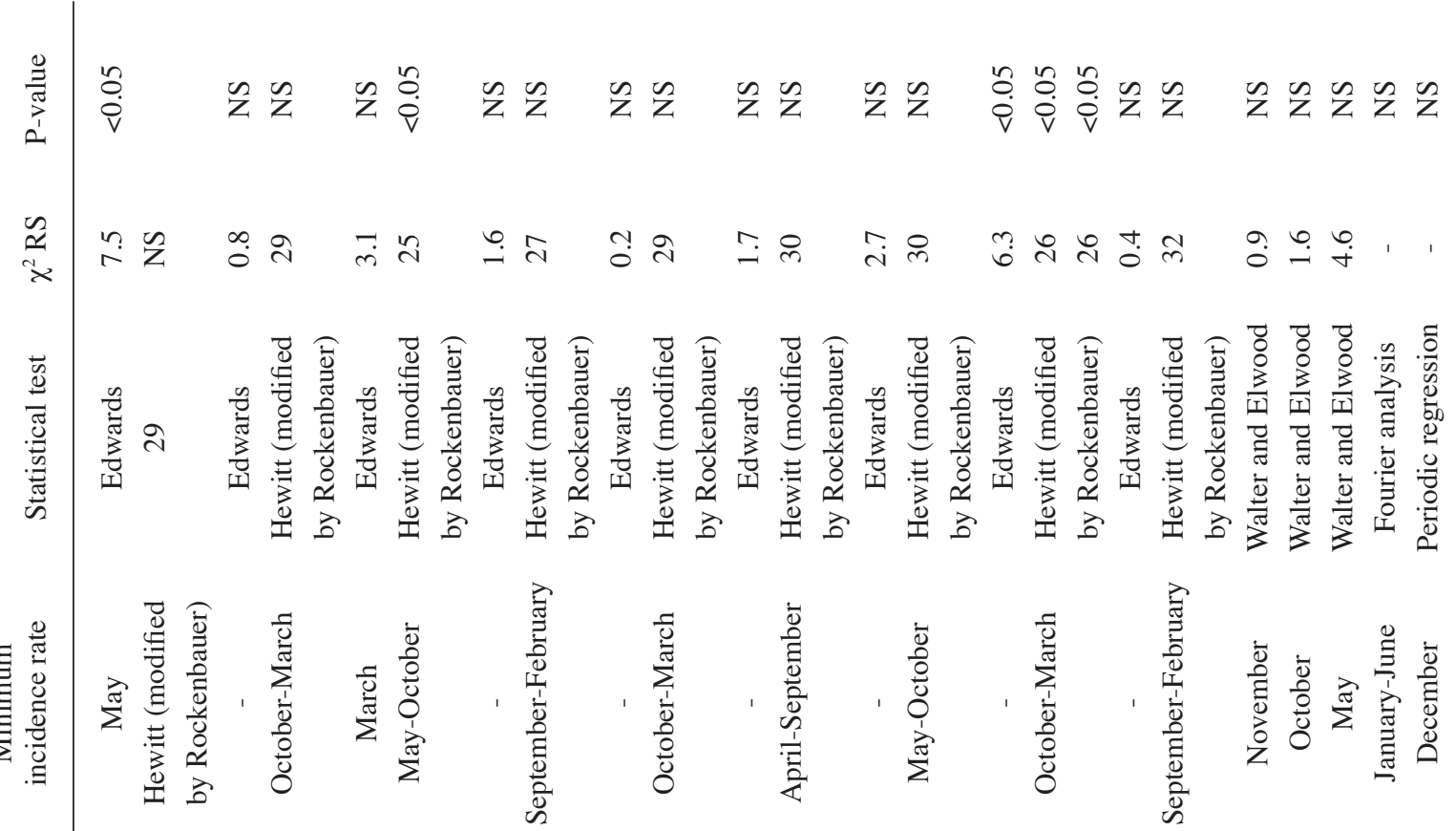

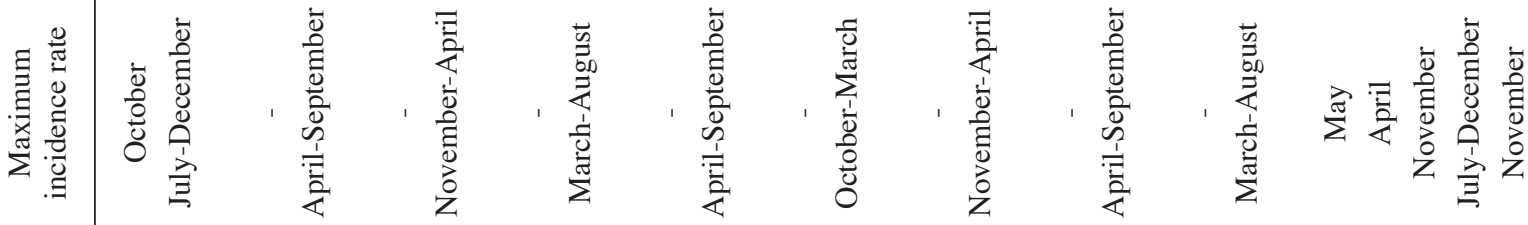

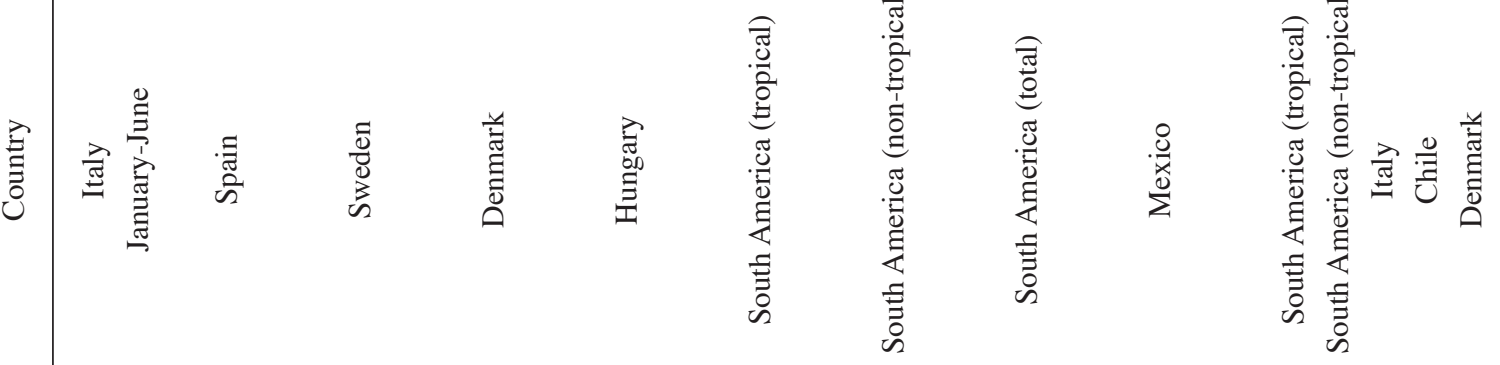

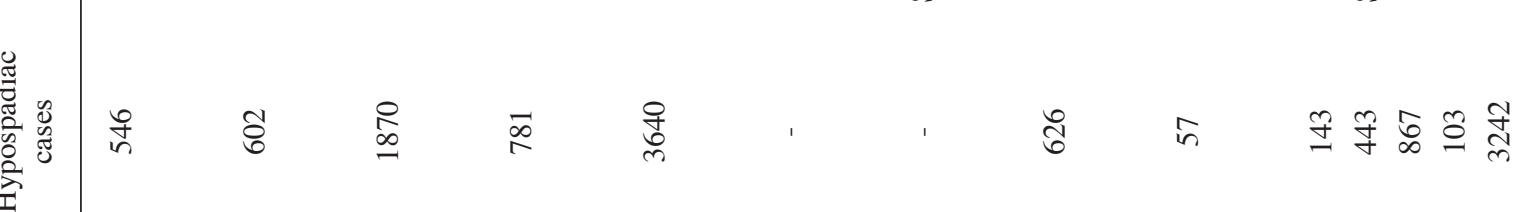

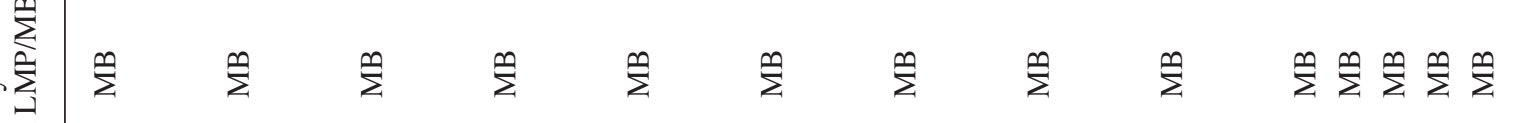
密

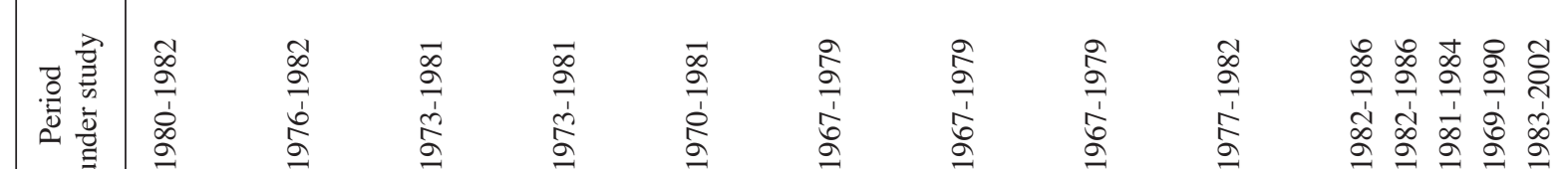


i.e., reports on monthly hypospadiac prevalence (21) or season of birth (22) among other risk factors, were not taken into consideration. The included reports in chronological order of publication and the main results are summarised in Table II (7-9,16,18,19,23-37).

The literature search revealed a marked paucity of data during the past decade. The LSS run, filtered for the past 10 years, yielded 577 reports; none however met the criteria set for being taken into consideration in the present study. The seasonality of hypospadias has therefore been studied worldwide, particularly in the past, which facilitates the comparability of our results in terms of a relative closer accrual period of time (1991-1998). Results have been however conflicting (Table II) $(7-9,16,18,19,23-37)$. Some authors found significant variations with respect to $\mathrm{MB}$ or the last menstrual period (LMP) $(7,18,19,23,27-29,31,36,38)$, whereas others did not $(8,9,16,24-26,30,32-35,37)$. Our analysis was based on MB. When malformed infants have a markedly shorter gestational length than normal ones, the study on MB can be skewed by seasonality in total births. It would be more correct to study seasonality in conceptions (LMPs), although this is often impossible. For hypospadias, this 'error' is minor and it is better to study MB to obtain more reliable data (29). Pre-term delivery has been reported as a risk factor $(31,32,35)$. Others have not observed differences in gestational length between normal/hypospadiac infants $(27,38)$. Low birth weight is possibly associated with hypospadias $(7,26,27,29,31,35)$. It has been shown that the risk associated with low gestational age is attributed to the association between gestational weeks (GW) and low birth weight.

We noted that HB follow a simple harmonic type pattern (both Edwards' and RS test gave significant results). The literature review revealed a number of studies suffering from serious limitations. Results based exclusively on $\chi^{2}$-of-heterogeneity $(24,26,33,34,36)$ cannot be unequivocally accepted. Results based exclusively on Edwards' test $(7,18,35)$ are questioned. Our results are methodologically comparable with six reports only $(19,23,29,31,37,38)$. Three of them evaluated the significance of Hewitt's test results using loose criteria and interpretation is troublesome $(23,29,31)$. According to Hewitt (11), it is appropriate to distinguish the situation in which a prior hypothesis specifying the six-month period of higher expected incidence is available for testing, from that in which the likely nature of any seasonality has to be inferred from the data. Values of the test criterion $\geq 50$ (later corrected by Rockenbauer to 52) and $\geq 55$ should be considered significant at the conventional $5 \%$ level for the former and the later situation, respectively (12).

Angerpointner (23) detected a seasonal pattern (peak between April/May) by performing both Edwards' and Hewitt's test. RS was not stated, but the result was considered statistically significant $(\mathrm{P}<0.007)$. However, $\mathrm{P}<0.007$ corresponds to $\mathrm{RS}=54$ for a pre-assigned segment of six months (11). Thus, the result should not have been considered significant. Källén et al (29) and Monteleone Neto et al (31) considered Hewitt's test result significant if $R S \geq 52$ (or $\leq 26$ : Hewitt's modified test) and $\mathrm{RS} \geq 50$, respectively without testing a particular pre-existing hypothesis for a given six-month period of higher expected prevalence. Therefore, seasonality has not been documented for any country under investigation in these studies $(11,12)$.
In a previous Greek study (37), no significant pattern was detected by Edwards' or Hewitt's test. Nevertheless, Edwards' criterion indicated an identical peak to ours (mid-October). During an 11-year period (1955-1965), 38,623 live and stillborn male infants were born at Alexandra University Maternity Hospital, Athens. There were 145 hypospadiac cases (prevalence $\sim 0.375 \%$ ). Total male live-births during this period were 875,672 . Based on these figures, we estimated that $\sim 3,284$ hypospadiac cases were born during 1955-1965. Therefore, the study was based on $\sim 4.5 \%$ of the total sample. With the reservation that the prevalence of hypospadias has remained relatively constant in Greece over the past decades (secular trends of hypospadias in Greece have not been investigated yet), it is estimated that our sample size covered $\sim 34.3 \%$ of hypospadiac cases born in Greece during this period. Edwards' test power, given our sample size/SV magnitude $(\alpha=0.171)$, is estimated at $\sim 70 \%$ at the $5 \%(20)$, whereas the test power in the previous Greek study (37) is estimated at $\sim 30 \%$ (underpowered).

Mediterranean countries, with a similar climate to Greece such as Italy and Spain, failed to detect any seasonal patterns. Considering a direct (e.g., daylight, temperature)/ indirect (e.g., diet influenced by temperature) seasonal effect, one would expect similarity to our results. However, the detected trend was moderate $(\alpha=0.171)$. Even with a sample size of $34.3 \%$, the chance for detection was limited $(70 \%)$. Possibly, previous analyses $(16,29)$ were hampered by small sample sizes. In Italy, both studies concluded that October (29) and November (16) had the highest birth prevalence, with the former yielding significance, which cannot be unequivocally accepted. SV was also reported in Spain (29). The reported peak (April) in non-tropical South America (16) is consistent with our results (southern hemisphere; 6-month difference in phase). In Scandinavia, the lowest HB prevalence was also observed in spring (29). These interesting, yet statistically insignificant results warrant further investigation.

The strict use of tools designed for the investigation of seasonality in congenital malformations, makes our results directly comparable with two reports only $(19,38)$, concluding that hypospadiac conceptions in South Wales follow a temporal pattern described by a simple harmonic curve $\left(\chi_{\text {Edward } s}^{2}=14.125, \mathrm{RS}=55\right.$; peak in November $)$. Our results are compatible with the observation of a higher prevalence of hypospadiac conceptions in winter, since the LMP of a woman delivering in October is usually in January. To explain the winter peak, the authors proposed that SV in daylight length may act detrimentally during the third phase of organogenesis (growth of genitalia between 12-16 GW) via alterations to maternal pineal gland function, causing alterations to melatonin secretion that may influence maternal pituitary, ovarian hormonal activity/hormonal balances with a negative effect on fetal testicular androgen production (theory of light) $(19,38)$.

Meteorological data derived from small countries, such as Greece are usually less disputable due to robustness throughout the country. The parameters investigated varied seasonally (maximal sunlight-temperature in summer/minimal in winter, maximal rainfall in winter/minimal in summer) and were strongly associated. Therefore, the theory of light $(19,38)$ cannot be rejected; however, a negative effect of low temperature or high rainfall can also be considered plausible. Although the theory of light cannot be directly rejected, it seems inappropriate to 
explain our results. The identical pattern observed in Greece and Wales and potentially in other Northern European countries, implies that seasonal differences in daylight length do not play an important role in the pathogenesis of hypospadias, since these countries are characterised by more prominent differences in daylight length among seasons compared to Greece. Furthermore, a study investigating SV of cryptorchidism in Greece, provided evidence against the theory of light (39). A role of low winter temperature via a decrease in maternal serum human chorionic gonadotrophin (hCG) profiles at the beginning of the androgen-dependent inguinoscrotal phase of testicular descent (26th GW) was proposed to explain the peak observed in March (39).

Considering the significantly increased prevalence of $\mathrm{HB}$ in October, it appears that the coincidence of the beginning of the 8th GW, with late winter is associated with increased hypospadiac prevalence. The hCG peak, Leydig cell development, androgen receptor expression, testosterone secretion, dehydrotestosterone (DHT) formation and genitalia differentiation, all begin during 8th-9th GW (40). Low temperatures during that period may be related to urethral folds failure to fuse during subsequent weeks, leading to hypospadias. During the differentiation of male genital tract, placental hCG stimulates fetal testicular androgen production. The hCG peak starting at the 8th GW just precedes the beginning of Leydig cell formation, testosterone secretion and DHT conversion (9th GW) (40). A decline in hCG secretion by the 18th GW follows, by which fetal pituitary gonadotropin production is mainly responsible for future testicular stimulation. Since normal urethral development is androgen-dependent, it appears that low temperatures at the 8 th GW are accompanied by a decrease in maternal hCG profiles detrimentally affecting subsequent embryonic Leydig cell secretory function/androgen production. Others have shown that maternal hCG during early pregnancy is significantly lower in winter compared to summer (41). The decreased embryonic Leydig cell secretory function may result in increased hypospadiac prevalence. This hypothesis is supported by the decreased prevalence in April. Our results revealed that the occurrence of the 8th GW in August is accompanied by a decreased hypospadiac prevalence. It may be suggested that high temperatures at the 8th GW do not influence maternal/fetal hormonal profiles/balances with overall result a minimal disturbance on of urethral folds fusion in the following weeks.

This hypothesis is set for the first time and could explain results not only in parts of Southern Europe, such as Greece and possibly Italy, but also in Northern Europe (Wales) and perhaps in other continents too (non-tropical South America) (Table II) (7-9,16,18,19,23-37). Furthermore, it is consistent with previous findings on the seasonal pattern of cryptorchid births in Greece (39). It seems that hypospadiac and cryptorchid births follow consistent seasonal patterns characterised by the coincidence of the beginning of the two fetal testicular androgen-dependent periods crucial for the normal differentiation of human male external genitalia and the inguinoscrotal phase of testicular descent (8th and 26th GW, respectively) with months of lower temperature (winter period). This hypothesis may also be consistent with the concept of testicular dysgenesis syndrome (TDS) (42). Relatively lower levels of placental hCG during winter acting upon a dysgenetic testis (borderline Leydig cell function) possibly result in disproportionally lower androgen production. If these relatively lower placental hCG levels are observed earlier or later in gestation (8-9th or 26th GW) hypospadias or cryptorchidism may develop, respectively. The presence of TDS symptoms may vary with severity of the underlying testicular dysgenesis. In mild forms, the restoration of hCG levels during months of higher temperature results to either normal penis formation or fully descended testes. In severe forms (severely suffering Leydig cell), low androgen production is independent of hCG levels and the final result will possibly be the combination of hypospadias and cryptorchidism. Nevertheless, further research is warranted in order such a hypothesis to be established.

In conclusion, HB prevalence follows a simple harmonic seasonal pattern and is associated with that of cryptorchidism in Greece. The coincidence of the first or third trimester of a potentially genetically influenced gestation with winter may lead to the phenotypic expression of hypospadias or cryptorchidism, respectively. The potential role of a cyclic-varied androgen-production stimulator, such as hCG may be speculated. The seasonality of a common environmental factor may contribute to these seasonal patterns and possibly to a common pathogenesis of these two congenital malformations.

\section{Acknowledgements}

The authors would like to thank Dr M. Petrakis, Director of IERSD and Dr D. Founta, Researcher of IERSD for the provision of the meteorological data, Mrs. A. Katsamani, Secretary of IERSD and Mrs. D. Pantartzi, Scientific Secretary of the Clinical Trial Office, Department of Urology, University of Crete Medical School for the administrative and technical support.

\section{References}

1. Bergman JE, Loane M, Vrijheid M, Pierini A, Nijman RJ, Addor MC, Barisic I, Béres J, Braz P, Budd J, et al: Epidemiology of hypospadias in Europe: A registry-based study. World J Urol 33: 2159-2167, 2015.

2. Baskin LS, Himes K and Colborn T: Hypospadias and endocrine disruption: is there a connection? Environ Health Perspect 109: 1175-1183, 2001.

3. Wang MH and Baskin LS: Endocrine disruptors, genital development, and hypospadias. J Androl 29: 499-505, 2008.

4. Liu D, Shen L, Tao Y, Kuang Y, Cai L, Wang D, He M, Tong X, Zhou S, Sun J, et al: Alterations in gene expression during sexual differentiation in androgen receptor knockout mice induced by environmental endocrine disruptors. Int J Mol Med 35: 399-404, 2015.

5. Bonde JP, Flachs EM, Rimborg S, Glazer CH, Giwercman A, Ramlau-Hansen CH, Hougaard KS, Høyer BB, Hærvig KK, Petersen SB, et al: The epidemiologic evidence linking prenatal and postnatal exposure to endocrine disrupting chemicals with male reproductive disorders: a systematic review and metaanalysis. Hum Reprod Update 23: 104-125, 2016.

6. Michalakis M, Tzatzarakis MN, Kovatsi L, Alegakis AK, Tsakalof AK, Heretis I and Tsatsakis A: Hypospadias in offspring is associated with chronic exposure of parents to organophosphate and organochlorine pesticides. Toxicol Lett 230: 139-145, 2014.

7. Avellán L: On aetiological factors in hypospadias. Scand J Plast Reconstr Surg 11: 115-123, 1977.

8. Calzolari E, Contiero MR, Roncarati E, Mattiuz PL and Volpato S: Aetiological factors in hypospadias. J Med Genet 23: 333-337, 1986.

9. Skriver MV, Pedersen L, Stang P, Lund L, Rothman KJ and Sørensen HT: The month of birth does not affect the risk of hypospadias. Eur J Epidemiol 19: 1135-1136, 2004. 
10. Edwards JH: The recognition and estimation of cyclic trends. Ann Hum Genet 25: 83-87, 1961.

11. Hewitt D, Milner J, Csima A and Pakula A: On Edwards' criterion of seasonality and a non-parametric alternative. Br J Prev Soc Med 25: 174-176, 1971.

12. Rockenbauer M: On criteria of seasonality. Periodica Polytechnica 22: 125-129, 1978.

13. Walter SD and Elwood JM: A test for seasonality of events with a variable population at risk. Br J Prev Soc Med 29: 18-21, 1975.

14. Frangakis CE and Varadhan R: Confidence intervals for seasonal relative risk with null boundary values. Epidemiology 13 734-737, 2002.

15. Petridou E, Papadopoulos FC, Frangakis CE, Skalkidou A and Trichopoulos D: A role of sunshine in the triggering of suicide. Epidemiology 13: 106-109, 2002.

16. Castilla EE, Orioli IM,Lugarinho R, Dutra GP,Lopez-Camelo JS Campana HE, Spagnolo A and Mastroiacovo P: Monthly and seasonal variations in the frequency of congenital anomalies. Int J Epidemiol 19: 399-404, 1990.

17. Stolwijk AM, Straatman H and Zielhuis GA: Studying seasonality by using sine and cosine functions in regression analysis. J Epidemiol Community Health 53: 235-238, 1999.

18. Wehrung DA and Hay S: A study of seasonal incidence of congenital malformations in the United States. Br J Prev Soc Med 24: 24-32, 1970.

19. Roberts CJ, Lowe CR and Lloyd S: Cyclic variations in date of last menstrual period of mothers of infants with congenital malformations in South Wales, 1964-66. Br J Prev Soc Med 26: 212-218, 1972

20. WalterSD: The power of a test for seasonality. Br JPrev Soc Med 31: 137-140, 1977.

21. Agopian AJ, Langlois PH, Ramakrishnan A and Canfield MA: Epidemiologic features of male genital malformations and subtypes in Texas. Am J Med Genet A 164A: 943-949, 2014.

22. Mohammadzadeh A, Farhat A, Esmaieli $\mathrm{H}$ and Shiranzaei S: Prevalence and risk factors of hypospadias in a private hospital in northeast Iran. Iran J Pediatr 21: 497-501, 2011.

23. Angerpointner TA: Hypospadias - genetics, epidemiology and other possible aetiological influences. Z Kinderchir 39: 112-118, 1984.

24. Bailo U, Beolchini PE and Ballestrin L: Observations on the seasonal variations in the frequency of congenital malformations. Minerva Ginecol 18: 1223-1231, 1966.

25. Campbell H, Newcombe RG and Weatherall JA: Epidemiology of simple hypospadias. BMJ 3: 52-53, 1973.

26. Chen YC and Woolley PV Jr: Genetic studies on hypospadias in males. J Med Genet 8: 153-159, 1971.

27. Czeizel A, Tóth J and Erodi E: Aetiological studies of hypospadias in Hungary. Hum Hered 29: 166-171, 1979.
28. Harlap S and Davis AM: Letter: Epidemiology of hypospadias BMJ 4: 235, 1973.

29. Källén B, Bertollini R, Castilla E, Czeizel A, Knudsen LB, Martinez-Frias ML, Mastroiacovo P and Mutchinick O: A joint international study on the epidemiology of hypospadias. Acta Paediatr Scand Suppl 324: 1-52, 1986.

30. Leung TJ, Baird PA and McGillivray B: Hypospadias in British Columbia. Am J Med Genet 21: 39-50, 1985.

31. Monteleone Neto R, Castilla EE and Paz JE: Hypospadias: An epidemiological study in Latin America. Am J Med Genet 10: $5-19,1981$.

32. Nazer J, Cifuentes L, Hubner ME, Ramírez R, Ruiz G, Pizarro MT, Nazer C and Morales I: Epidemiologic study of factors associated with hypospadias. Rev Med Chil 120: 244-249, 1992.

33. Record RG and Armstrong E: Epidemiology of simple hypospadias. BMJ 3: 233, 1973.

34. Slater BC, Watson GI and McDonald JC: Seasonal variation in congenital abnormalities. Preliminary report of a survey conducted by the Research Committee of Council of the College of General Practitioners. Br J Prev Soc Med 18: 1-7, 1964.

35. Sweet RA, Schrott HG, Kurland R and Culp OS: Study of the incidence of hypospadias in Rochester, Minnesota, 1940-1970, and a case-control comparison of possible etiologic factors. Mayo Clin Proc 49: 52-58, 1974.

36. Theander G: Seasonal distribution of births of boys with anomalies of the urethra. Scand J Urol Nephrol 4: 1-5, 1970.

37. Trichopoulos D, Cadas C, Kalapothaki V and Pimenidou E: Letter: Epidemiology of hypospadias. BMJ 4: 109, 1973.

38. Roberts CJ and Lloyd S: Observations on the epidemiology of simple hypospadias. BMJ 1: 768-770, 1973.

39. Mamoulakis Ch, Antypas S, Stamatiadou A, Demetriadis D, Kanakas N, Loutradis D, Miyagawa I, Yannakis D, Kaponis A, Tzonou A, et al: Cryptorchidism: Seasonal variations in Greece do not support the theory of light. Andrologia 34: 194-203, 2002.

40. Sultan C, Paris F, Terouanne B, Balaguer P, Georget V, Poujol N Jeandel C, Lumbroso S and Nicolas JC: Disorders linked to insufficient androgen action in male children. Hum Reprod Update 7: 314-322, 2001.

41. Kiely EA, Chapman RS, Bajoria SK, Hollyer JS and Hurley R: Maternal serum human chorionic gonadotrophin during early pregnancy resulting in boys with hypospadias or cryptorchidism. Br J Urol 76: 389-392, 1995.

42. Skakkebaek NE, Rajpert-De Meyts E and Main KM: Testicular dysgenesis syndrome: An increasingly common developmental disorder with environmental aspects. Hum Reprod 16: 972-978, 2001. 